\title{
Measuring physical activity during pregnancy - Cultural adaptation of the Pregnancy Physical Activity Questionnaire (PPAQ) and assessment of its reliability in Polish conditions
}

\author{
Justyna Krzepota', Dorota Sadowska', Katarzyna Sempolska², Małgorzata Pelczar³ \\ ${ }^{1}$ Department of Physical Culture and Health Promotion, University of Szczecin, Poland \\ ${ }^{2}$ Infrastructure and Management College in Warsaw, Poland \\ ${ }^{3}$ Faculty of Computer Science and Information Technology, West Pomeranian University of Technology Szczecin, Poland
}

Krzepota J, Sadowska D, Sempolska K, Pelczar M. Measuring physical activity during pregnancy - Cultural adaptation of the Pregnancy Physical Activity Questionnaire (PPAQ) and assessment of its reliability in Polish conditions. Ann Agric Environ Med. $2017 ; 24(4)$ : 640-643. doi: $10.5604 / 12321966.1228390$

\begin{abstract}
I Abstract
Introduction and objective. The assessment of physical activity during pregnancy is crucial in perinatal care and it is an important research topic. Unfortunately, in Poland there is a lack of one commonly accepted questionnaire of physical activity during pregnancy.

The aim of this study was to adapt the Pregnancy Physical Activity Questionnaire (PPAQ) to Polish conditions and assess the reliability of its Polish version (PPAQ-PL).

Materials and method. The PPAQ was translated from English into Polish and its reliability tested. 64 correctly completed (twice, one week apart) questionnaires were qualified for analysis. Test-retest reliability was assessed using Intraclass Correlation Coefficient (ICC).

Results. As a result of the adaptation and psychometric assessment, in the Polish version of the questionnaire the number of questions was reduced from 36 to 35 by removing the question concerning 'mowing lawn while on a riding mower'. The ICC value for total activity was 0.75 , which confirms a substantial level of reliability. The ICC values for subscales of intensity ranged from 0.53 (light) -0.86 (vigorous). For subscales of type, ICC values ranged from 0.59 (transportation) -0.89 (household/caregiving).

Conclusions. The PPAQ-PL can be accepted as a reliable tool for the assessing physical activity of pregnant women in Poland. Information obtained using the questionnaire might be helpful in monitoring health behaviours, preventing obesity, as well as designing and promoting physical activity programmes for pregnant women.
\end{abstract}

\section{Key words}

physical activity, pregnancy, questionnaire, cultural adaptation

\section{INTRODUCTION}

Taking into consideration evidence that exercise during pregnancy causes positive physiological and psychological changes $[1,2,3,4]$, the assessment of physical activity of pregnant women is an important research topic. Formulating recommendations concerning the type, duration and intensity of physical activity during pregnancy is therefore of paramount importance for the health of both the mother and her child $[5,6]$.

Despite its limitations, the questionnaire remains the most popular method in the assessment of physical activity in population research [7]. Nevertheless, using one questionnaire for all research samples, without consideration for unique qualities of a given group, proves to be insufficient. Consequently, the indicates the need to use physical activity questionnaires designed for specific groups, taking into consideration the nature of energy expenditure, possibilities and restrictions concerning physical activity (e.g.

Address for correspondence: Justyna Krzepota, Department of Physical Culture and Health Promotion, University of Szczecin, Poland

E-mail: justyna.krzepota@univ.szczecin.pl

Received: 7 August 2014; accepted: 17 October 2014; first published on December, 2016 questionnaires for pregnant women [8,9], and questionnaires assessing physical activity of children and youths, adults or elderly people [10]).

Designing such a questionnaire is not an easy task [11]. Moreover, its adaptation to cultural conditions needs to follow a set of detailed rules [12,13]. Adaptation of a well-designed questionnaire to cultural conditions makes it possible to use the same research method in different countries. This, in turn, allows the comparison of results and creation of large-scale intervention and health promotion programmes.

The Pregnancy Physical Activity Questionnaire (PPAQ) is one of the few currently available questionnaires for assessing the physical activity of pregnant women [9] and has gained international recognition and has been adapted for use in different countries $[14,15,16,17]$.

In Poland, the assessment of physical activity during pregnancy has become popular only recently. Consequently, there is a lack of one commonly accepted questionnaire and research shows inconsistencies in methodological approaches $[18,19,20,21]$. As a result, there is a need to design a standardized tool which would enable researchers to compare and interpret their results. 


\section{OBJECTIVE}

The aim of this study was to adapt the PPAQ to Polish conditions and assess the reliability of its Polish version (PPAQ-PL).

\section{MATERIAL AND METHODS}

The questionnaires were filled-in voluntarily by pregnant women participating in organised forms of physical activity in Warsaw. 64 correctly completed (twice, one week apart) questionnaires were qualified for analysis. The respondents were aged $25-41(31.8 \pm 3.8), 98.4 \%$ of them had higher education and $1.6 \%$ secondary education. The majority of the participants $(98.4 \%)$ came from Warsaw, and only $1.6 \%$ from its environs. $82.8 \%$ of the respondents were married, $15.6 \%$ were single, and $1.6 \%$ divorced. $81.3 \%$ had no children, $15.6 \%$ had one child, and $3.1 \%$ had more than one.

The chosen research method was the PPAQ questionnaire, a tool devised by Chasan-Taber et al. [9] to self-assess physical activity of pregnant women during the current trimester. In this semi-quantitative questionnaire, the respondents are asked to report the time spent participating in 33 types of activities that can be grouped under the following categories: household/caregiving (13 activities), occupational (5 activities), sports/exercise ( 9 activities), transportation (3 activities), and inactivity (3 activities). The PPAQ helps to determine the duration, frequency, and intensity of total activity throughout pregnancy, and trace activity patterns in pregnant women. The participants are asked to choose the category that best approximates the amount of time spent on each activity per day or week during the given trimester. The options they can select range from $0-6$ or more hours per day, and from 0-3 or more hours per week.

The respondents filled-in the questionnaire twice, one week apart. The time for completing the questionnaire was unlimited. Research was approved by the Bioethics Committee.

Research procedure. The first step after having receiving written permission from the author of the PPAQ, was to have the original version of the questionnaire translated into Polish by two different translators whose mother tongue is Polish and who are fluent in English. The next step was to agree on one version of the questionnaire in Polish, and then translate it back into English. Back-translation was carried out independently by two English native speakers. The translated versions proved to be equivalent to the original. The first 3 questions in the questionnaire concern the date of delivery, and the remaining part related to different types of physical activity undertaken by the respondents. In the final stage of questionnaire adaptation and psychometric assessment, the Polish version underwent linguistic correction and the number of questions was reduced from 36 to 35 (with the author's permission), by removing the question concerning 'mowing lawn while on a riding mower', since in Poland this activity is very rare.

The reliability was assessed by test-retest, conducted one week apart. Carrying out the research on the same group twice, using the same tool, is a widespread method for assessing reliability. The test-retest was evaluated by using the Intraclass Correlation Coefficient (ICC), with ICC values
$>0.8$ indicating high reliability and ICC values in the range of 0.6-0.8 representing substantial reliability [22].

Statistical analysis was performed with the use of statistical package Statistica 10.0 PL.

\section{RESULTS}

The data obtained from the questionnaires completed in a one-week interval were converted into energy expenditure, measured in MET-h/week, as suggested by the PPAQ authors. Table 1 shows the median, $25^{\text {th }}$ and $75^{\text {th }}$ percentile values for total activity and its two subscales, i.e. intensity and type of activity, in PPAQ $1^{\text {st }}$ and PPAQ $2^{\text {nd }}$, respectively.

Table 1. Median, $25^{\text {th }}$ and $75^{\text {th }}$ percentile values (MET-h/week) for total activity and subscales of activity in PPAQ $1^{\text {st }}$ and PPAQ $2^{\text {nd }}$

\begin{tabular}{lcccccc}
\hline \multirow{2}{*}{ Activity } & \multicolumn{5}{c}{ PPAQ $1^{\text {st }}$ (MET-h/week) } & \multicolumn{3}{c}{ PPAQ $2^{\text {nd }}$ (MET-h/week) } \\
\cline { 2 - 7 } & $25^{\text {th }}$ & Median & $75^{\text {th }}$ & $25^{\text {th }}$ & Median & $75^{\text {th }}$ \\
\hline Summary activity scores: & & & & & & \\
\hline Total activity & 172.08 & 214.64 & 274.38 & 149.24 & 192.35 & 248.93 \\
\hline By intensity: & & & & & & \\
\hline Sedentary (<1.5 METs) & 62.04 & 95.03 & 118.52 & 42.70 & 78.40 & 105.96 \\
\hline Light (1.5 - <3.0 METs) & 56.70 & 74.73 & 102.51 & 54.86 & 70.53 & 92.71 \\
\hline Moderate (3.0-6.0 METs) & 24.43 & 49.48 & 68.66 & 23.83 & 45.53 & 67.86 \\
\hline Vigirous (>6.0 METs) & 0.00 & 0.00 & 1.63 & 0.00 & 0.00 & 1.63 \\
\hline By type: & & & & & & \\
\hline Household/caregiving & 40.47 & 61.34 & 86.28 & 39.03 & 53.03 & 77.88 \\
\hline Occupational activity & 0.00 & 0.00 & 102.77 & 0.00 & 0.00 & 92.23 \\
\hline Sports/exercise & 13.28 & 17.95 & 29.94 & 12.35 & 17.80 & 28.09 \\
\hline Transportation & 14.66 & 27.13 & 36.97 & 14.00 & 24.94 & 35.88 \\
\hline
\end{tabular}

The study results obtained show that the median for total activity was 214.64 in PPAQ $1^{\text {st }}$ and 192.35 in PPAQ $2^{\text {nd }}$. Taking into consideration the intensity of physical activity, the highest median result in both questionnaires was obtained for sedentary activity (95.03 in PPAQ $1^{\text {st }}$ and 78.40 in PPAQ $\left.2^{\text {nd }}\right)$, while the lowest result was reflected in the vigorous category (0.00 in PPAQ $1^{\text {st }}$ and 0.00 in PPAQ $\left.2^{\text {nd }}\right)$. As far as the type of physical activity is concerned, the respondents exhibited the highest energy expenditure in household/caregiving activities (61.34 in PPAQ $1^{\text {st }}$ and 53.03 in PPAQ $2^{\text {nd }}$ ).

Test-retest reliability between the two questionnaires (PPAQ $1^{\text {st }}$ and PPAQ $2^{\text {nd }}$ ), completed at a one-week interval, was assessed using Intraclass Correlation Coefficient (Tab. 2). The ICC value for total activity was 0.75 , which confirms a substantial level of reliability. The ICC values for subscales of intensity ranged from 0.53 (light) -0.86 (vigorous). For subscales of type, ICC values were higher, ranging from 0.59 (transportation) - 0.89 (household/caregiving).

The degree of agreement between PPAQ $1^{\text {st }}$ and PPAQ $2^{\text {nd }}$ was illustrated using Bland-Altman plot (Fig. 1). The limits of agreement were calculated as a mean difference between the investigated indices \pm 1.96 for standard deviation of difference [23]. 
Table 2. Intraclass Correlation Coefficient (ICC) between PPAQ $1^{\text {st }}$ and PPAQ $2^{\text {nd }}$

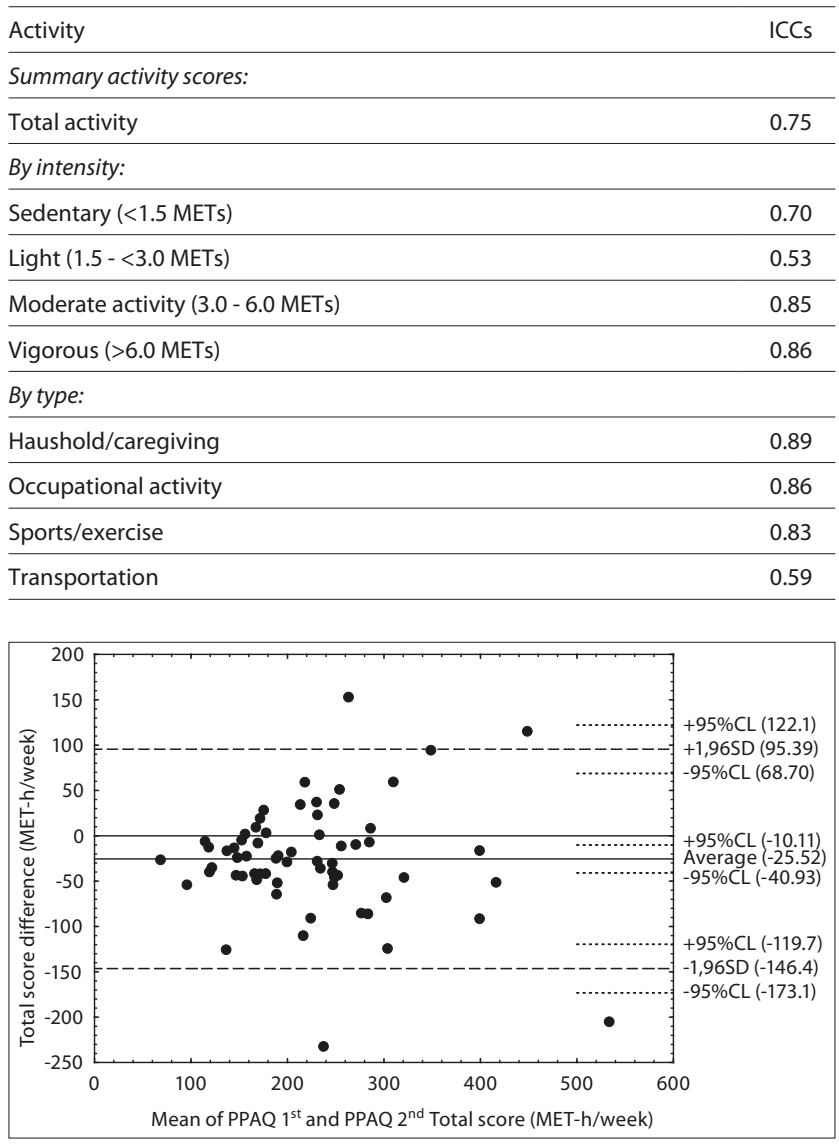

Figure 1. Bland-Altman plot of PPAQ $1^{\text {st }}$ and PPAQ $2^{\text {nd }}$ total score

\section{DISCUSSION}

As a result of recent recommendations [5, 24, 25], the assessment of physical activity during pregnancy has become a widely discussed topic. To the best of the knowledge of the authors, the presented study is the first attempt to adapt a tool for assessment of physical activity during pregnancy to Polish conditions. The PPAQ was translated from English into Polish and its reliability tested. Consequently, a Polish version of the questionnaire was drafted. Due to some cultural differences, the question concerning 'mowing lawn while on a riding mower' was removed from the questionnaire, which reduced the number of questions in the Polish version from 36 to 35 . This activity is not only extremely rare in Polish urban areas, where the respondents live, but also in the countryside. It can be seen that in the process of cultural adaptation of the questionnaire, other researchers also introduced some modifications $[14,15,16,17]$. In the Vietnamese version [16] 'mowing lawn using a walking mower, raking and gardening' was removed, since these activities are not widespread in Vietnam. On the other hand, since most of the people commute to work or other places on a bicycle or motorbike, and cars are not very popular, 'riding a bicycle to go places (such as the bus, work, or school) not for fun or exercise' was introduced. The authors also replaced ' $a$ car' with 'a motorbike', with 'driving or riding on a motorbike or bus'. In Chandonnet et al. [17], a study conducted in the francophone province of Quebec, Canada, the same question, 'mowing lawn using a walking mower, raking and gardening', related to outdoor chores, was adapted to the specificities of climate in Canada by including a winter outdoor activity, 'shoveling snow". In the 'Going Places' section of the Japanese PPAQ [14], the authors added 'riding a bicycle for reasons other than for recreation or excercise (to catch a bus, to go to work, or to visit a place, etc.)", since the bicycle is the basic means of transportation for Japanese women. They also changed ' 1 gallon milk jug' to ' $3 \mathrm{~kg}$ bag of rice'. In the Polish version, gallons were replaced with liters, since the latter is the unit of measurement commonly used in Poland.

It is worth noting that at the end of the 'Sports and Exercises' section there are two open questions, which make it possible for the respondents to report any unlisted activities. This enables the researchers to take into account both outdoor and indoor activities characteristic for a given community, depending on its geographical location, climate and cultural determinants. Chandonnet et al. [17] noted that women participating in their research were able to give additional information concerning winter outdoor activities (e.g. snowshoeing and skiing).

In earlier studies $[9,15,16,17]$, the reliability of PPAQ was measured by comparing results obtained by the test-retest method or contrasting them with results obtained using other methods (e.g. pedometer, actigraph). In the presented research, the test-retest method at one-week interval was applied.

In other adaptations of the PPAQ, the Intraclass Correlation Coefficient values for total activity were 0.90 [17], 0.88 [16] and 0.78 [9], respectively. In the current study, the ICC was 0.75 , which indicates substantial test-retest reliability of the PPAQ in Polish conditions.

Compared to previous adaptations of the questionnaire in other countries $[15,16,17]$, the presented results are closest to the French version of PPAQ [17], as far as energy expenditure in MET-h/week is concerned. Nevertheless, the results obtained in the current research are slightly higher, which can probably be explained by differences in the research sample. Chandonnet et al. [17] conducted research among obese women, while the respondents in the current study were physically active women, participating in organized forms of physical activity for pregnant women.

There are several shortcomings in the presented research that should be noted that result from the homogeneity of the research sample. Firstly, the respondents were more physically active than most pregnant women in Poland. Secondly, all of them lived in a big city and had higher education. Therefore, it would be advisable to assess psychometric properties of the questionnaire on a more representative sample, including women at different stages of pregnancy, living in different environments and having different levels of education.

\section{CONCLUSIONS}

Despite the limitations of the presented research, the PPAQPL can be accepted as a reliable tool for assessing the physical activity of pregnant women in Poland. Information obtained using the questionnaire might be helpful in monitoring health behaviours, preventing obesity, as well as designing and promoting physical activity programmes for pregnant women. 


\section{REFERENCES}

1. Brown W. The benefits of physical activity during pregnancy. J Sci Med Sport.2002; 5(1): 37-45.

2. Sternfeld B, Quesenberry CP Jr, Eskenazi B, Newman LA. Exercise during pregnancy and pregnancy outcome. Med Sci Sports Exerc.1995; 27(5): 634-640.

3. Sternfeld B. Physical activity and pregnancy outcome. Review and recommendations. Sports Med.1997; 23(1): 33-47.

4. Szumilewicz A, Wojtyła A, Zarębska A, Drobnik-Kozakiewicz I, Sawczyn M, Kwitniewska A. Influence of prenatal physical activity on the course of labour and delivery according to the new Polish standard for perinatal care. Ann Agric Environ Med. 2013; 20(2): 380-389.

5. ACOG Committee Obstetric Practice. ACOG Committee opinion. Number 267, January 2002: exercise during pregnancy and the postpartum period. Obstet Gynecol. 2002; 99(1): 171-173.

6. Smith KM, Campbell CG. Physical activity during pregnancy: impact of applying different physical activity guidelines. J Pregnancy. 2013; ID 165617. doi: 10.1155/2013/165617.

7. Sallis JF, Saelens BE. Assessment of physical activity by self-report: status, limitations, and future directions. Res Q Exerc Sport. 2000; 71(2 Suppl): S1-14.

8. Schmidt MD, Freedson PS, Pekow P, Roberts D, Sternfeld B, ChasanTaber L. Validation of the Kaiser Physical Activity Survey in pregnant women. Med Sci Sports Exerc. 2006; 38(1): 42-50.

9. Chasan-Taber L, Schmidt MD, Roberts DE, Hosmer D, Markenson G, Freedson PS. Development and validation of aPregnancyPhysica Activity Questionnaire. Med Sci Sports Exerc. 2004; 36(10): 1750-1760.

10. Pereira MA, Fitzer Gerald SJ, Gregg EW, Joswiak ML, Ryan WJ, Suminski RR, et al. A collection of Physical Activity Questionnaires for health-related research. Med Sci Sports Exerc. 1997 Jun; 29(6 Suppl): S1-205.

11. Aday LA, Llewellyn JC. Designing and conducting health surveys: a comprehensive guide. John Wiley \& Sons Publishers, 2011.

12. Beaton DE, Bombardier C, Guillemin F, Ferraz MB. Guidelines for the process of cross-cultural adaptation of self-report measures. Spine (Phila Pa 1976). 2000; 25(24): 3186-3191.

13. Guillemin F, Bombardier C, Beaton D. Cross-cultural adaptation of health-related quality of life measures: literature review and proposed guidelines. J Clin Epidemiol. 1993; 46(12): 1417-1432.
14. Matsuzaki M, Haruna M, Ota E, Yeo S, Murayama R, Murashima S. Translation and cross-cultural adaptation of the Pregnancy Physical Activity Questionnaire (PPAQ) to Japanese. Biosci Trends. 2010; 4(4): $170-177$.

15. Matsuzaki M, Haruna M, Nakayama K, Shiraishi M, Ota E, Murayama $\mathrm{R}$, et al. Adapting the Pregnancy Physical Activity Questionnaire for Japanese pregnant women. J Obstet Gynecol Neonatal Nurs. 2014; 43(1): 107-116.

16. Ota E, Haruna M, Yanai H, Suzuki M, Anh DD, Matsuzaki M, et al. Reliability and validity of the Vietnamese version of the Pregnancy Physical Activity Questionnaire (PPAQ). Southeast Asian J Trop Med Public Health. 2008; 39(3): 562-570.

17. Chandonnet N, Saey D, Alméras N, Marc I. French Pregnancy Physical Activity Questionnaire compared with an accelerometer cut point to classify physical activity among pregnant obese women. PLoS One. 2012; 7(6): e38818. doi: 10.1371/journal.pone.0038818.

18. Wojtyła A, Kapka-Skrzypczak L, Paprzycki P, Skrzypczak M, Biliński P. Epidemiological studies in Poland on effect of physical activity of pregnant women on the health of offspring and future generations adaptation of the hypothesis development origin of health and diseases. Ann Agric Environ Med. 2012; 19(2): 315-326.

19. Ćwiek D, Szczęsna M, Malinowski W, Fryc D, Daszkiewicz A, Augustyniuk K. Analiza aktywności fizycznej podejmowanej przez kobiety w czasie ciąży. PNiG. 2012; 5(1): 51-54.

20. Makara-Studzińska M, Kryś-Noszczyk K, Starczyńska M, Sieroń A, Śliwiński Z. Types of physical activity during pregnancy. Pol Ann Med. 2013; 20(1): 19-24.

21. Rutkowska E, Łepecka-Klusek C. The role of physical activity in preparing women for pregnancy and delivery in Poland. Health Care Women Int. 2002; 23(8): 919-923.

22. Bushnell CD, Johnston DC, Goldstein LB. Retrospective assessment of initial stroke severity: comparison of the NIH Stroke Scale and the Canadian Neurological Scale. Stroke. 2001; 32(3): 656-660.

23. Altman DG, Bland JM. Measurement in medicine: the analysis of method comparison studies. J Roy Stat Soc D-Sta.1983; 32: 307-317.

24. Davies GA, Wolfe LA, Mottola MF, MacKinnon C, Arsenault MY, Bartellas E, et al. SOGC Clinical Practice Obstetrics Committee, Canadian Society for Exercise Physiology Board of Directors. Exercisein pregnancy and the postpartum period. J Obstet Gynaecol Can. 2003; 25(6): 516-529.

25. Zavorsky GS, Longo LD. Exerciseguidelinesin pregnancy: new perspectives. Sports Med. 2011; 41(5): 345-360. 